\title{
DIÁLOGOS ENTRE POLÍTICAS PÚBLICAS E A FORMAÇÃO DE PROFESSORES LEITORES
}

\author{
Elianeth Dias Kanthack Hernandes ${ }^{1}$ \\ Renata Junqueira De Souza² \\ Alberto Albuquerque Gomes ${ }^{3}$
}

\begin{abstract}
Resumo
Os grupos de pesquisa Formação de Professores e as relações entre as práticas educativas em leitura, literatura e avaliação do texto literário e Profissão Docente - Formação, Identidade e Representações Sociais, buscando estabelecer um diálogo profícuo e interdisciplinar, têm agregado, ao seu rol de estudos, as pesquisas na área da política nacional de leitura e política educacional no Brasil. Ao estudar os desdobramentos do Plano Nacional de Biblioteca na Escola (PNBE) e de relacionar os dados obtidos com um mapeamento do perfil dos alunos em formação docente para atuação no 1 음ivel da educação básica e anos/séries iniciais do Ensino Fundamental, procuramos ampliar os conhecimentos sobre os efeitos de diversas políticas públicas na formação de professores. A perspectiva que orienta este trabalho é que o diálogo entre diferentes grupos auxiliam a ampliar os conhecimentos sobre o objeto de pesquisa.
\end{abstract}

Palavras-chave: Política Pública. Formação de leitores. Formação de professores. PNBE.

\section{DIALOGUE BETWEEN PUBLIC POLICIES AND TEACHER TRAINING READERS}

\begin{abstract}
Research groups Teacher Training and the relationship among education in reading, literature and evaluation of literary texts and Teaching Profession - Training, Identity and Social Representations, seeking to establish a fruitful and interdisciplinary dialogue, have added to their studies list the research in national reading policy and educational policy in Brazil. When studying the unfolding of the National Library Plan in School (PNBE in Portuguese acronym) and to relate the data obtained with a
\end{abstract}

\footnotetext{
${ }^{1}$ Professora Assistente de Doutor da Universidade Estadual Paulista Júlio de Mesquita Filho - UNESP - Campus de Marília - RDIDP- lotada no Departamento de Administração e Supervisão Escolar. Com Doutorado em Educação (2008) e Mestrado (2003), ambos realizados no Programa de Pós Graduação em Educação da Universidade Estadual Paulista Júlio de Mesquita Filho- Marília. Supervisora de Ensino aposentada, tendo atuado como professora de educação básica, Diretora de Escola e Supervisora de Ensino na rede Estadual de São Paulo durante 33 anos. Tem experiência na área de Educação, com ênfase em Avaliação de Sistemas, Instituições, Planos e Programas Educacionais, atuando principalmente nos seguintes temas: formação docente, capacitação, formação de gestores, ação supervisora e supervisores de ensino. E-mail: <netezeu@gmail.com>.

${ }^{2}$ Livre-docente no conjunto das disciplinas Conyeúdos, Metodologia e Prática de Ensino de Língua Portuguesa I e II, e Leitura e Literatura e Interpretação de textos no processo de formação de professores, Doutora em Letras.Mestre em Linguística e Letras pela UNESP/ Marília; Professora Doutora da UNESP-PP, professora visitante da Universidade do Minho/PT e professora colaboradora no Programa de Pós Graduação em Letras da Universidade Federal do Espírito Santo (UFES). E-mail: <recellij@gmail.com>.

${ }^{3}$ Professor do Programa de Pós-graduação em Educação (Mestrado e Doutorado) e do curso de Pedagogia da Faculdade de Ciências e Tecnologia - UNESP. Membro do Conselho Editorial da revista Nuances (Presidente Prudente). Graduado em Ciências Sociais pelo Centro de Estudos Superiores de Londrina (1983), mestrado em Educação (1993) e doutorado em Educação (1998) pela Universidade Estadual Paulista Júlio de Mesquita Filho. Estágio de pós-doutoramento em Sociologia da Educação na Universidade Lusófona de Humanidades e Tecnologias em Lisboa, Portugal (2003/2004). E-mail: <alberto@fct.unesp.br>.
} 
students' profile mapping in teacher training for operations in the $1^{\text {st }}$ level of Basic Education and early years/grades of Elementary School, we seek to expand knowledge on the effects of various public policies in teacher education. The perspective that guides this work is the dialogue among different groups helps to broaden the knowledge about the object of research.

Keywords: Public Policy. Training of players. Teacher training; PNBE.

\section{DIÁLOGOS ENTRE POLÍTICAS PÚBLICAS Y EL ENTRENAMIENTO DE PROFESORES LECTORES}

\section{Resumen}

Los grupos de investigación Formação de Professores e as relações entre as práticas educativas em leitura, literatura e avaliação do texto literário y Profissão Docente - Formação, Identidade e Representações Sociais, em la búsqueda por establecer un diálogo rentable e interdisciplinario tiene agregado, a su lista de estudios, las investigaciones en el área de la política nacional de lectura y política educacional en Brasil. En estudiar los desdoblamientos del Plan Nacional de Biblioteca en la Escuela (PNBE) y de relacionar los datos obtenidos con un mapeo de perfil de los alumnos en formación docente para actuación en el $1 \mathfrak{0}$ nivel da educación básica y años/series iniciales de la Enseñanza Fundamental, procuramos ampliar los conocimientos sobre los efectos de diversas políticas públicas en el entrenamiento de profesores. La perspectiva que orienta este trabajo es que el diálogo entre diferentes grupos auxilian a ampliar los conocimientos sobre el objeto de investigación.

Palabras-clave: Política Pública. Formación de lectores. Entrenamiento de professores. PNBE.

\section{Introdução}

Este estudo procura apontar algumas possibilidades de interlocução entre diferentes grupos de pesquisadores focados em temáticas variadas - neste caso, relações entre práticas educativas em leitura, literatura e avaliação do texto literário e políticas públicas para formação de professores.

Busca apontar a produção de discursos que se aproximam e interpenetram, embora tratem de temáticas variadas. Partimos do pressuposto que a possibilidade de interlocução e aproximação se estabelece considerando que não podemos falar de práticas educativas e formação de professores, sem falar de políticas públicas.

A seguir, descrevemos suscintamente a gênese dos grupos de pesquisa aos quais nos referiremos ao longo deste texto.

\section{Dois grupos de pesquisa distintos: as investigações e o encontro}


Elianeth Dias Kanthack Hernandes

Renata Junqueira De Souza

Alberto Albuquerque Gomes

Em 2001, foi criado e consolidado o Grupo de Pesquisa Formação de Professores e as relações entre as práticas educativas em leitura, literatura e avaliação do texto literário, com o objetivo de pesquisar o ensino da leitura na educação fundamental e, consequentemente, seus desdobramentos nas formas de avaliação desse processo. $\mathrm{O}$ alcance desse trabalho e dos inúmeros projetos que foram financiados, ao longo desse tempo, por órgãos governamentais de fomento, têm saído das fronteiras do município de Presidente Prudente (através do intercâmbio entre nosso Grupo e pesquisadores de outras cidades brasileiras) e também chegado ao além-mar (intercâmbio com países como Canadá, EUA, Portugal e Espanha).

Nos últimos anos, com a intenção de ampliar os conhecimentos sobre o ensino da leitura no Brasil, o grupo de pesquisa tem agregado, de forma recorrente, pesquisadores da área da política educacional, pela importância que o entendimento das políticas voltadas para a formação de leitores tem, com vistas a consolidar as pesquisas dessa área de estudo.

Além de buscar uma abordagem interdisciplinar, as pesquisas deste grupo constituem-se a partir de propostas de estudos qualitativos e quanti-qualitativos, e lançam mão de múltiplos métodos de produção e análise de dados, agenciando e correlacionando fontes materiais plurais (escritas, orais, visuais e sincréticas).

Do ponto de vista das fontes, utilizamos a pesquisa bibliográfica: documentos oficiais (leis, decretos, pareceres, parâmetros, diretrizes, orientações curriculares, projetos político-pedagógicos, matrizes curriculares, ementários, planos de curso); documentos que são produzidos e/ou circulam na formação (livros, apostilas, esquemas/resumos, cópias em geral, slides, provas, cadernos escolares, trabalhos, relatórios, fotos, vídeos); entrevistas estruturadas e semiestruturadas, depoimentos (escritos e orais) e questionários abertos e fechados com os respectivos tabelamentos de dados; observação e vivência das práticas na universidade e, eventualmente, na escola, e registros em diários de campo, filmagens, fotografias, etc.

Na perspectiva desse grupo de pesquisa, a escolha de qualquer tema, problema, questão, método, fonte/corpus, teoria e a proposição e divulgação de conclusões, é política. Neste sentido, os lugares de onde nos posicionamos implica que todo trabalho de investigação é colaborativo e dialógico, e se desdobra com a expectativa de um tratamento ético (responsável e responsivo dos dados): requer, pois, um olhar generoso para os envolvidos, 
para o tema, para as fontes, para os interlocutores, para a socialização de resultados, que não tome os sujeitos das pesquisas apenas como informantes, mas como parceiros fundamentais do processo de constituição do ser-pesquisador e da história das instituições em que o trabalho se realiza.

De igual modo, inspirados pela perspectiva enunciativo-discursiva e pela filosofia da linguagem nascida do Círculo de Bakhtin (2009), o texto é o ponto de partida e de chegada do trabalho de pesquisa: não são analisados fragmentos de textos, mas unidades de sentido em seus contextos de produção, circulação e recepção. O sentido não é dado, constitui-se conforme a perspectiva da Estética da Recepção e da Teoria do Efeito Estético, na articulação entre texto-leitor, razão pela qual deslocamos o polo que conferia centralidade ao produtor de enunciados, privilegiando a escuta, a atividade de leitura, a recepção.

Inspirados por perspectiva histórico-cultural, entendemos que as percepções, símbolos, impressões e devaneios são tão importantes quanto os dados objetivos e factuais, porque constituem, de igual modo, a realidade, e que não se pode vincular imediatamente classe e cultura porque, historicamente, as apropriações dos bens, objetos e saberes culturais são mais fluidas.

Consideramos que todo dado, informação ou contribuição teórica é indício importante de realidade e merece ser pensado, no contexto, com toda a seriedade e empenho, também à sua própria revelia (mediante uma abordagem a contrapelo). Tendo em vista que lidamos com sujeitos de diferentes formações e histórias profissionais, inseridos em contextos múltiplos de investigação, fica evidente a necessidade de que as pesquisas nos mobilizem e façam sentido para o contexto sócio, histórico e cultural em que estamos inseridos.

Esperamos, com essas posturas, fomentar formações teórico-metodológicas regulares, com leitura de textos, discussões e debates. Almejamos que os protagonistas e os sujeitos de pesquisas envolvidos leiam as produções escritas uns dos outros e atuem como leitores críticos, que intervêm nos produtos alheios de maneira (pro)positiva.

Com essas perspectivas e conceitos norteadores, iniciamos estudos sobre o Programa Nacional de Biblioteca na Escola (PNBE), que registramos a seguir com o propósito de ampliar o entendimento sobre as políticas de leitura no Brasil. 
Por outro lado, o grupo de pesquisa Profissão docente: formação, identidade $e$ representações sociais agrega um conjunto de pesquisadores e estudantes que, há algum tempo, estudam e refletem sobre a questão de formação de professores para Educação Infantil e Ensino Fundamental e sobre a construção da identidade profissional desses professores. Os trabalhos desenvolvidos, individual e coletivamente pelos membros do grupo, tem resultado em teses, dissertações, artigos e textos apresentados em eventos científicos buscando, contribuir para o debate sobre o tema. A organização do grupo busca congregar esses estudos em projetos coletivos, que contribuam para o amadurecimento dos membros do grupo e formação de jovens pesquisadores.

Prioritariamente, o grupo propõe-se a investigar os aspectos específicos da formação inicial de professores para as séries/anos do Ensino Fundamental, tais como: saberes necessários para o exercício da docência; expectativas de futuros professores quanto ao futuro profissional; importância dos estágios supervisionados para o futuro exercício da profissão; além de estimular a produção de pesquisas sobre a inserção dos licenciandos em Pedagogia no cotidiano da escola básica e sobre as possibilidades da formação centrada na escola como política de formação continuada de professores.

A partir da complementaridade que percebemos nos objetos de estudo desses dois grupos de pesquisa, o de política de formação de leitores e o de política de formação de professores, procuramos, nos limites deste trabalho, analisar um dos programas governamentais de maior visibilidade e amplitude, no que diz respeito à formação de leitores, o Plano Nacional de Biblioteca na Escola (PNBE).

\section{O Plano Nacional de Biblioteca na Escola em análise}

O PNBE é um programa único no mundo pela sua dimensão e alcance em termos de investimentos e distribuição de acervos literários às escolas públicas. Considerando o contexto de políticas e programas de leitura, é um programa singular, se comparado à política do livro ${ }^{4}$ em outros países, em virtude de sua complexidade, recursos financeiros investidos,

\footnotetext{
4. Em 30 de outubro de 2003 foi publicada a lei $n^{\circ}$ 10.753, que institui a Política Nacional do Livro, que define, em seu Artigo $1^{\circ}$, Parágrafo I, a necessidade de "assegurar ao cidadão o pleno exercício do direito de acesso e uso do livro"(BRASIL, 2003).
} 
quantidade de obras adquiridas e pela dimensão geográfica do Brasil, que abarca milhares de escolas públicas.

A primeira edição do PNBE aconteceu em 1998, com obras selecionadas por mestres e doutores que lecionam em universidades federais, "profissionais com múltiplas experiências, entre as quais a docência na educação básica e a formação de professores" (BRASIL/FNDE, 2014, p. 1). ${ }^{5}$ As edições do PNBE sofreram mudanças desde o envio da primeira remessa de livros às escolas, em 1998. De inicio, pensou-se na possibilidade de enviar acervos às comunidades locais para que fossem constituídas bibliotecas comunitárias nos municípios, e bibliotecas pessoais nas casas dos estudantes e dos professores. À medida que o tempo passou, priorizou-se o envio de livros às escolas para a formação de bibliotecas, o que permanece até os dias atuais.

Toda a estrutura montada pelo PNBE atrai ávidos editores que tentam se adequar para que possam ser aceitos nos editais divulgados anualmente. Houve, em 2005, em função de críticas ao Programa, alterações no edital, que ampliou para 60 o número de editoras selecionadas, o que não aplacou a irritação de editores de livros escolares.

As editoras pequenas, ainda que nos últimos anos tenham tido a chance de se inscrever no PNBE, concorrem com as mais poderosas, em uma luta desigual. Em 2006 foram inscritas 1.718 obras no PNBE e selecionadas 225 (PAIVA, 2012). Das 170 editoras que participaram do processo de seleção, foram escolhidas 70, e 100 editores ficaram à margem.

Mesmo a entrada, nos últimos anos, de editoras pequenas no processo de seleção dos acervos do PNBE, não alterou o monopólio. Ainda são as maiores editoras que têm suas obras eleitas em grandes quantidades. Isso significa que uma editora menor concorrerá com grupos poderosos, que possuem várias editoras com selos distintos, inúmeros títulos inscritos em cada edital e larga experiência no mercado editorial (PAIVA, 2012).

Como qualquer outro produto, o livro também passa pelo processo de análise e aprovação da Associação Brasileira de Normas Técnicas (ABNT). Acontece, também, uma avaliação para checagem das exigências técnicas. Segundo Paiva (2012), cada parecerista recebe de 16 a 20 obras variadas e deve considerar três critérios básicos de seleção: qualidade

\footnotetext{
5. Todas as informações referentes ao PNBE encontram-se, permanentemente, no site do Ministério da Educação: http://www.fnde.gov.br/programas/biblioteca-da-escola/biblioteca-da-escolaapresentacao.
} 
Elianeth Dias Kanthack Hernandes Renata Junqueira De Souza Alberto Albuquerque Gomes

do texto, adequação temática e projeto gráfico, que priorizem as preocupações estéticas e de conteúdo, bem como a capacidade de o livro despertar o interesse do jovem leitor. Terminada essa etapa e enviados os livros às escolas, desponta um problema ainda não resolvido pelos formuladores das políticas públicas sobre o ensino da leitura: quem vai ler os livros?

Nas primeiras edições do PNBE, os professores podiam escolher o que parecia ser mais adequado para a formação do aluno-leitor, a partir da listagem que lhes era apresentada. A partir de 2005, deixaram de participar do processo de escolha dos títulos e, portanto, não há o envolvimento da comunidade escolar na escolha, nem há capacitação e divulgação das obras nas escolas.

O Tribunal de Contas da União iniciou, em 1998, um trabalho de auditorias relacionado aos programas do Governo Federal, entre eles o PNBE. "A auditoria objetivou investigar se o PNBE poderia ter seus propósitos atendidos de forma mais efetiva caso houvesse uma melhor utilização dos livros" (BRASIL/TCU, 2003, p. 3). A partir da auditoria do TCU, o MEC encomendou uma pesquisa-diagnóstico do Programa Nacional Biblioteca da Escola (PNBE): leitura e biblioteca nas escolas públicas brasileiras, publicada em 2008. A pesquisa alcançou 65\% dos 5.560 municípios do país e identificou que o PNBE se mantém, basicamente, como "um grande programa de distribuição de livros, sem apoio de projetos de formação continuada de professores que tivesse o objetivo de repensar a formação de leitores pelas escolas públicas brasileiras" (BRASIL/MEC, 2008, p. 14).

Em artigo publicado na revista Pro-Posições, intitulado Programa Nacional Biblioteca da Escola (PNBE) - uma avaliação diagnóstica, as professoras e elaboradoras da pesquisa, Jane Paiva e Andréa Berenblum, da UFRJ, que coordenaram o estudo diagnóstico do PNBE, explicam que ter o livro na escola não significa formar leitores. "Nos casos em que esses materiais são utilizados", explicam as autoras, "o trabalho pedagógico continua marcado por uma forte tendência à decomposição de textos para o estudo de gramática prescritiva, em busca de respostas corretas e únicas interpretações para a leitura" (PAIVA; BERENBLUM, 2009, p. 182).

A não utilização dos acervos do PNBE e a falta de mediadores de leitura nas escolas, sejam eles professores, bibliotecários, entre outros, que, se preparados para a tarefa, poderiam revolucionar a leitura na escola pública, evidenciam que, em algum momento do processo, há discrepância entre o que se pensou e o que é viável na prática diária das escolas. 
Pesquisas feitas no Oeste Paulista (SOUZA, et all, 2009), sobre o local dos acervos nas escolas de três municípios daquela região, indicou que os livros do PNBE, muitas vezes, ficam nas salas dos gestores da escola, trancados. Outras vezes, quando vão para as prateleiras da biblioteca escolar, são separados por estantes e anos escolares, o que impede um leitor do poder da escolha. Há, ainda, em muitas das bibliotecas visitadas - um sentimento de pertencimento ao livro, ou seja, o professor readaptado, ou o responsável pelo acesso dos leitores em formação ao objeto livro não permite a livre escolha, ou até mesmo a visita às prateleiras da biblioteca. Quando os alunos chegam para a retirada semanal de um livro, encontram uma seleção de obras já disponibilizadas em mesas (geralmente, selecionam-se os livros mais velhos, usados e pouco convidativos para o ato de ler) e não podem buscar outra obra, tendo a escolha limitada e o não acesso aos livros dos acervos do PNBE. Faltam, neste espaço, aquele do conhecimento - a biblioteca escolar - orientações e formação específica sobre a importância do livro, da escolha e dos elementos que seduzem o leitor em formação (capa, paratextos, ilustrações, materialidade do objeto), bem como informações sobre a organização e o funcionamento da biblioteca.

Diante dessa realidade, entranhada na história de educação pública brasileira, percebe-se claramente que toda a vida em sociedade é fruto de decisões políticas, e com a leitura não seria diferente. Como se observa a partir dos dados gerados, o problema-chave, que se torna evidente, é o distanciamento do PNBE da realidade das escolas. A comunidade escolar recebe os livros, mas os desconhece, e o uso que se poderia fazer dos acervos, bem como a realização de atividades de promoção da leitura, não está previsto nas rotinas das salas de aula e, assim, aqui se poderia indagar: por que a Política de Estado de leitura ainda não conseguiu se tornar realidade nas escolas?

Destaca-se, ainda, a morosidade na definição da política de mediação da leitura e da formação de profissionais capazes de desempenhar esse papel dentro das escolas. As páginas das obras continuam fechadas, à espera de leitores. Se a formação de professores leitores não está sendo priorizada em um programa político, da envergadura e custos do PNBE, julgamos necessário analisar, também, quais os aspectos que podem ser destacados na formação docente que tem sido oferecida em diferentes espaços acadêmicos, suas aproximações e tensionamentos com as demandas contemporâneas com vistas a uma educação de qualidade. 


\section{Políticas públicas para formação de professores da Escola Básica}

As ações de democratização do ensino verificadas nas últimas décadas evidenciaram todo um processo de passagem de uma sociedade tradicional, que precisava se organizar para possibilitar o acesso aos segmentos historicamente excluídos, direitos como educação e saúde, dentre outros.

Entretanto, embora a escola pública tenha sido ampliada quantitativamente, não estava preparada para receber e atender a toda a população e a diversidade que a ela adentrava. Porém, precisamos destacar, apoiando-nos em Beiseguel (1980, p. 50): “Quem defende a democratização do ensino não pode recusar, não pode criticar a qualidade do aluno de nossa escola... não podemos mudar a população... Precisamos fazer com que a escola passe a responder a essa população."

Concomitantemente ao processo de democratização do ensino, temos acompanhado, também, uma série de mudanças como consequência do processo denominado Globalização, entendido como "a intensificação de reações sociais mundiais que ligam comunidades distantes, de modo que acontecimentos locais são moldados por eventos que ocorrem a muitas milhas de distância e vice-versa nos aspectos político, econômico e cultural." (MORROW; TORRES, 2004, p. 54).

Os estudos sobre as políticas públicas para a formação de professores para a escola básica tem se consolidado, notadamente a partir da década de 1980, com maior ênfase nas primeiras décadas do recém-iniciado século XXI. Esses estudos têm demonstrado que tais políticas sociais podem ser associadas ao processo de expansão e ampliação do acesso ao ensino público e gratuito nas últimas décadas do século XX.

Leite e Di Giorgi (2004, p. 1) chamam a atenção para esse fato informando que,

[...] nos últimos anos, houve uma grande expansão das oportunidades de acesso à escola pública, promovendo o atendimento de quase todas as crianças no ensino fundamental. A escola pública para poucos, no passado, cedeu lugar à escola para muitos, no presente. 
Considerando esse aspecto, o papel do Estado na formulação de políticas públicas para atender às demandas dos segmentos sociais que chegam à escola pública torna-se estratégico e fundamental, pois

[...] esta ampliação quantitativa não veio acompanhada de medidas e de ações essenciais que garantissem a melhoria qualitativa do ensino. Quase todas as escolas ainda mantêm uma estrutura organizacional tradicional, conservadora, pautada em princípios burocratizantes, que dificultam a adoção de novas práticas pedagógicas pelos professores. A escola com a sua organização e a sua cultura burocratizadora e centralizadora, condiciona a prática dos professores, impossibilitando que se manifestem como sujeitos sociais e profissionais (LEITE; DI GIORGI, 2004, p. 1).

Portanto, a escola vê-se diante da necessidade urgente de rever seu trabalho no sentido de atender as exigências da sociedade atual, com seus notáveis avanços tecnológicos, difusão e circulação muito rápida de informações, mudanças no processo de produção e organização do trabalho, alterações nas concepções de Estado e suas funções, mudança no paradigma das ciências e do conhecimento, agravamento da exclusão social, crise ética e enfraquecimento do papel socializador da família, além da ampliação do atendimento, destacada anteriormente.

Esses são pontos importantes para serem pensados por nós, educadores, e podem servir como alternativas para repensar o papel da escola para atender essas novas demandas. Além disso, não podemos perder de vista os atores principais deste processo os professores. E a sua formação? Como tem acontecido e como deveria estar estruturada para atender a esse novo panorama?

Diante desses questionamentos e inquietações foi conduzida, no período compreendido entre 2011 e 2014, uma pesquisa cujo objetivo geral foi mapear o perfil dos alunos em formação docente para atuação no 1ำ nível da Educação Básica e anos/séries iniciais do Ensino Fundamental e de seus formadores, além de analisar e discutir propositivamente sobre as condições de formação na Faculdade de Ciências e Tecnologia da UNESP de Presidente Prudente, e no Campus do Pantanal da Universidade Federal do Mato Grosso do Sul. Os sujeitos da pesquisa foram alunos em processo de formação inicial matriculados no curso de formação de docentes, além dos professores formadores atuantes nos referidos cursos. 
Os apontamentos preliminares indicam que podem ser identificadas algumas semelhanças:

1. No que tange à questão do sexo, ratificando a tese de Gatti e Barreto (2009), da predominância de alunas nos cursos de Pedagogia. A docência, em sua origem, foi uma profissão eminentemente masculina, o que leva a afirmar que a feminização do magistério não é um acontecimento natural.

2. A falta de conhecimento prévio da estrutura curricular do curso é algo igualmente a ser destacado nas duas universidades, revelando que a opção pela carreira profissional é feita a partir de parâmetros externos associados à profissão, e não através da base que fundamenta o currículo acadêmico. Porém, a motivação em atuar na docência é algo comum e corriqueiro entre os alunos de ambas as cidades, situação que corrobora o estudo de Gatti e Barreto (2009), sobre o interesse motivacional que a profissão provoca.

3. Da mesma forma, o local de atuação profissional não é um consenso entre os alunos, sendo a distribuição de interesses algo comum, encontrado nos cursos das duas universidades.

4. Não foram identificadas diferenças quanto à origem dos alunos em relação à educação básica, predominando aqueles oriundos de escolas públicas entre ambas as universidades, fato que se liga às condições socioeconômicas dos grupos, demonstradas na discussão.

5. As grandes diferenças emergem da questão atinente ao sustento financeiro durante o curso de graduação, com diferenças significativas entre os alunos de Presidente Prudente e Corumbá. Reflexo do tipo de formação recebida (integral ou parcial), as diferenças nesse quesito refletem a história de vida desses alunos, sendo observado o ingresso precoce no mundo do trabalho dos alunos da cidade paulista, quando comparada à cidade sul-matogrossense.

Se, por um lado, fica evidente nos dois municípios, a maneira cega como os alunos escolheram o curso e, consequentemente, a profissão de professor; por outro, podemos evidenciar a falta de conhecimentos prévios culturais ideológicos e políticos para formarem crianças e, por conseguinte, leitores. 
Elianeth Dias Kanthack Hernandes

Renata Junqueira De Souza

Alberto Albuquerque Gomes

Concordamos com os teóricos, que têm defendido a necessidade de focar os aspectos que estão relacionados com a formação de professores para buscar alternativas de qualificação docente (TARDIF, 2002; FREIRE, 2001; GUIMARÃES, 2004; GATTI, 2010). Defendemos a ideia de que a formação plena como leitor é um dos aspectos fundamentais para obter a qualificação docente defendida por esses e outros teóricos. A falta de oportunidade de ampliar a cultura letrada, que deveria ser proporcionada nos espaços escolares, no acompanhamento e avaliação das políticas de distribuição de livros e nos programas de formação de professores pode explicar, no nosso entender, os resultados obtidos em outra questão, que também é objeto de nossas pesquisas, que analisaremos a seguir. Dos futuros professores que, ao serem indagados sobre a frequência com que leem, quando o objeto de leitura são outros textos, que não os das leituras necessárias para atividades escolares/acadêmicas, apenas a minoria dos respondentes afirmou que o fazem diariamente. Já cerca de $20 \%$ leem, nessas circunstâncias, semanalmente. O que mais surpreende é o fato de $32 \%$ dos futuros professores admitirem que nunca leem, ou só o fazem raramente, quando não precisam atender às demandas acadêmicas.

Em pesquisa financiada pela Fapesp, Souza, et AL (2009) encontraram professores não leitores, não conhecedores de textos literários. Os dados da pesquisa indicam a necessidade de investimentos em programas de formação do professor, não somente em relação a conteúdos específicos do ensino da lingual maternal, mas a aspectos de sua própria formação cultural, como a frequência a cinemas, teatros, a leitura e discussão de obras literárias de reconhecida qualidade, tanto as dirigidas para público adulto, quanto as que são consideradas como literatura infantil e juvenil. Os professores pesquisados, atuantes na região Centro-oeste do Estado de São Paulo, no Brasil, embora vivam e trabalhem no Estado mais desenvolvido economicamente do país, apresentam perfil cultural não compatível com a profissão exercida.

Outro aspecto preocupante constatado em levantamento longitudinal, realizado junto aos estudantes em processo de formação no curso de Pedagogia, ingressantes entre os anos de 2001 e $2004^{6}$, foi a pouca prioridade dedicada aos hábitos de leitura. Um dado a se destacar refere-se à faixa etária dos estudantes ingressantes (vide tabela 2). Observe-

${ }^{6}$ De 320 ingressantes, 194 estudantes responderam ao questionário aplicado em sala de aula. 
se que cerca de $65 \%$ dos sujeitos consultados encontrava-se na faixa etária entre 17 e 21 anos. Quando indagamos aos jovens ingressantes sobre seus hábitos em horários de lazer, constatamos dados preocupantes, no que diz respeito aos hábitos de leitura. Os hábitos de leitura ocupam a segunda preferência dos estudantes $(28,1 \%)$, percentual inferior àqueles que não apresentaram respostas ou apontaram outras atividades como dançar, passear, ir à igreja, etc.

Quanto ao tipo de literatura acessada, os sujeitos indicaram com frequência significativa textos de autoajuda, literatura religiosa e, em frequência inferior, os textos e livros indicados pelos professores do curso que frequentavam.

Essas informações, associadas às informações anteriores sobre o perfil cultural incompatível com a profissão docente (SOUZA, et al, 2009), revelam a necessidade de maiores investimentos na formação inicial e na formação de leitores.

Tabela 1 - ATIVIDADES DAS HORAS DE FOLGA

\begin{tabular}{|l|r|r|}
\hline CATEGORIAS & \multicolumn{1}{|c|}{ FREQUENCIA } & \multicolumn{1}{|c|}{ PERCENTUAL } \\
\hline ASSISTIR TV/OUVIR MÚSICA & 158 & 40,72 \\
LER LIVROS/JORNAIS/REVISTAS & 109 & 28,1 \\
OUTROS & 65 & 16,75 \\
NÃO RESPONDEU & 56 & 14,43 \\
Total & & 100 \\
\hline
\end{tabular}

Fonte: Pesquisa de campo - FCT/UNESP - Presidente Prudente - 2001/2004.

Tabela 2 - Faixa etária dos estudantes - 2001 - 2004

\begin{tabular}{|c|c|c|}
\hline Faixa Etária & Frequência & Percentual \\
\hline Não respondeu & 02 & 1,0 \\
\hline 17 & 13 & 6,7 \\
\hline 18 & 36 & 18,6 \\
\hline 19 & 36 & 18,6 \\
\hline 20 & 19 & 9,8 \\
\hline 21 & 19 & 9,8 \\
\hline 22 & 5 & 2,6 \\
\hline 23 & 11 & 5,7 \\
\hline 24 & 9 & 4,6 \\
\hline 25 & 3 & 1,54 \\
\hline 26 & 4 & 2,1 \\
\hline 27 & 4 & 2,1 \\
\hline
\end{tabular}


Elianeth Dias Kanthack Hernandes Renata Junqueira De Souza Alberto Albuquerque Gomes

\begin{tabular}{|c|c|c|}
\hline 28 & 6 & 3,1 \\
\hline 29 & 3 & 1,54 \\
\hline 30 & 1 & 0,5 \\
\hline 31 & 4 & 2,1 \\
\hline 32 & 2 & 1,0 \\
\hline 33 & 3 & 1,54 \\
\hline 34 & 1 & 0,5 \\
\hline 35 & 1 & 0,5 \\
\hline 36 & 3 & 1,54 \\
\hline 37 & 1 & 0,5 \\
\hline 38 & 1 & 0,5 \\
\hline 39 & 3 & 1,54 \\
\hline 40 & 1 & 0,5 \\
\hline 43 & 2 & 1,0 \\
\hline 49 & 1 & 0,5 \\
\hline Total & 194 & 100 \\
\hline
\end{tabular}

Fonte: Pesquisa de campo - FCT/UNESP - Presidente Prudente - 2001/2004.

Resta concluir que, se não existe diferença substancial entre o público que busca os cursos de formação de professores na Faculdade de Ciências e Tecnologia da UNESP de Presidente Prudente e no Campus do Pantanal da Universidade Federal do Mato Grosso do Sul, e se, ainda de acordo com nossas pesquisas, a maioria desses jovens não é formada por leitores habituais e proficientes, então, cabe indagar o papel de uma política de formação de leitores, como o PNBE, para alterar esse quadro de forma consequente.

Ao ser constatado que uma das razões da subutilização dos livros da coleção do PNBE nas instituições avaliadas é o despreparo da equipe de docentes e responsáveis pelas bibliotecas para colocar em prática atividades voltadas à formação de leitor na primeira infância (SOUZA, et al 2009), e ao ser verificado que, por isso, as páginas das obras continuam fechadas, à espera de leitores nas escolas de Educação Básica, o papel de formação de professores leitores na universidade ganha relevância que não pode ser ignorada.

\section{REFERÊNCIAS}

BAKHTIN, M. Marxismo e filosofia da linguagem. Problemas fundamentais do método sociológico na ciência da linguagem. Trad. Michel Lahud e Yara Frateschi Vieira. 13 ed. São Paulo: Hucitec, 2009. 
BEISIEGEL, C. R.. Relações entre a quantidade e a qualidade no ensino comum In: I Conferência Brasileira de educação, 1980.

BRASIL/TCU. Relatório do Primeiro Monitoramento Programa Nacional Biblioteca da Escola - PNBE. 6a Secretaria de Controle Externo/Secretaria de Fiscalização e Avaliação de Programas de Governo. Tribunal de Contas da União. Brasília: 2003. 22 p. <Disponível em: <http://portal2tcu.gov.br/portal/page/portal/TCU/comunidade/programas governo/areas_atuacao/educacao/Relat\%C3\%B3rio\%20primeiro\%20monitoramento\%20P NBE\%20\%C3\%BAltima\%20vers\%C3\%A3o.pdf> Acesso em: 8/12/2013.

BRASIL/MEC. Programa Nacional Biblioteca da Escola (PNBE): leitura e bibliotecas nas escolas públicas brasileiras. Secretaria de Educação Básica e Coordenação-Geral de Materiais Didáticos. Elaboração: BERENBLUM, A. e PAIVA, J.. Brasília: Ministério da Educação, 2008. 130 p. Disponível em:

$<$ http://portal.mec.gov.br/seb/arquivos/pdf/Avalmat/livro mec final baixa.pd>Acesso em: 24/9/2013.

BRASIL/FNDE. Programa Nacional Biblioteca da Escola (PNBE). Apresentação da Avaliação e seleção das obras. Brasília: Ministério da Educação, 2014. <Disponível em http://www.fnde.gov.br/programas/biblioteca-da-escola/biblioteca-da-escolafuncionamento>. Acesso em 13/6/2014.

FREIRE, P. Pedagogia da Autonomia: saberes necessários à prática educativa. São Paulo: Paz e Terra, 2001.

GATTI, B. A.; BARRETO, E. S. S. Professores do Brasil: impasses e desafios. Brasília. UNESCO, 2009.

GATTi, B. A. Formação de professores no Brasil: características e problemas. Educ. Soc., Campinas, v. 31, n. 113, p. 1355-1379, out.-dez. 2010. Disponível em http://www.scielo.br/pdf/es/v31n113/16.pdf. Acesso em 10/06/2015.

GUIMARÃES, V. S. Formação de professores: saberes, identidade e profissão. Campinas, Papirus, 2004.

LEITE, Y. U. F-; DI GIORGI, C. A. G.. Saberes docentes de um novo tipo na formação profissional do professor: alguns apontamentos. Educação (UFSM), v. 29, n. 2, maio/ago. 2004.

MORROW. R. A. E TORRES, C. A. Estado, Globalização e Políticas Educacionais. In: PALMA FILHO. J. C. e TOSI P. G. (Org.). Pedagogia Cidadã: Cadernos de Formação: Políticas e Economia da Educação. São Paulo: UNESP, Pró-reitoria de Graduação, 2004.

PAIVA, J. BeRENBLUM, A. Programa Nacional Biblioteca da Escola (PNBE) - uma avaliação diagnóstica. Pro-Posições. Vol. 20. № 1. Campinas (SP). Jan./Abr. 2009. 
DIÁLOGOS ENTRE POLÍTICAS PÚBLICAS E A FORMAÇÃO DE PROFESSORES LEITORES

Elianeth Dias Kanthack Hernandes

Renata Junqueira De Souza Alberto Albuquerque Gomes

SOUZA, R. J. et al. Relatório da pesquisa de Políticas Públicas A literatura na escola: espaços e contextos - a realidade brasileira e portuguesa, 2009. (FAPESP, 2006-2009)

TARDIF, M. Saberes Docentes e Formação Profissional. Petrópolis (RJ): Vozes, 2002.

RECEBIDO EM 31 DE AGOSTO DE 2015.

APROVADO EM 27 DE JULHO DE 2016. 